\title{
Compatible Ferroelectricity, Antiferroelectricity and Broadband Emission for a multi-functional 2D Organic-Inorganic Hybrid Per- ovskite
}

\author{
Wen-Juan Wei, ${ }^{* \dagger}$ Hong-Qiang Gao, ${ }^{\dagger}$ Yu-Hui Tan ${ }^{\dagger}$ and Yun-Zhi Tang*,† \\ ${ }^{\dagger}$ Engineering Research Institute, Jiangxi University of Science and Technology, Ganzhou 341000, China
}

\begin{abstract}
Two-dimensional (2D) organic-inorganic hybrid perovskites with multifunctional characteristics have potential applications in many fields, such as, solar cells, microlasers and light-emitting diodes (LEDs), etc. Here, a 2D organic-inorganic lead halide perovskite, $\left[\mathrm{Br}\left(\mathrm{CH}_{2}\right)_{3} \mathrm{NH}_{3}\right]_{2} \mathrm{PbBr}_{4}\left(\mathbf{B P A}-\mathbf{P b B r}_{4}, \mathrm{BPA}=\mathrm{Br}\left(\mathrm{CH}_{2}\right)_{3} \mathrm{NH}_{3}, 3\right.$-Bromopropylamine $)$, is examined for its photophysical properties. Interestingly, BPA-PbBr 4 reveals five successive phase transitions with decreasing temperature, including successive paraelectric-ferroelectric-antiferroelectric phases. Besides, BPA-PbBr 4 displays ferroelectricity and antiferroelectricity throughout a wide temperature range $(<376.4 \mathrm{~K})$ with accompanying saturation polrization $\left(P_{\mathrm{s}}\right)$ values of 4.35 and $2.32 \mu \mathrm{C} / \mathrm{cm}^{2}$, respectively, and energy storage efficiency of $28.2 \%$, and also exhibits superior second harmonic generation (SHG) with maximum value accounts for $95 \%$ of the standard KDP due to the great deformation of structure $\left(3.2302 * 10^{-4}\right)$. In addition, the photoluminescence (PL) of the BPA-PbBr 4 exhibits abnormal red-shift and blue-shift in different phases due to a consequence of competition between electron-phonon interaction and the lattice expansion. Further, BPA-PbBr 4 reveals a broadband emission accompanied by bright white light at room temperature $(293 \mathrm{~K})$, which is supposed to be due to self-trapped excitons. In short, the versatility of BPA-PbBr 4 originates from molecular reorientation of dynamic organic cations, as well as significant structural distortion of $\mathrm{PbBr}_{6}$ octahedra. This work paves an avenue to design new hybrid multifunctional perovskites for potential applications in the photoelectronic field.
\end{abstract}

\section{- INTRODUCTION}

Electroactive substances, as an indispensable basic component of advanced electronic devices, have the ability of energy stroage and conversion. ${ }^{1-2}$ Ferroelectrics are one of the important electroactive substances, which can realize spontaneous polarization $\left(P_{s}\right)$ storage and switching. ${ }^{3}$ The appearance of ferroelectricity leads to miscellaneous optoelectric effects, while the coupling of ferroelectric polarity with other physical properties brings new concepts for electronic and optoelectronic applications..$^{-6}$ Additional, antiferroelectrics have achieved an indispensable status in electroactive substances due to their inherent advantages of large storage capacity, which reveals a polarization versus electric field $(P-E)$ double hysteresis loops derived from the switching of antiparallel dipoles when subjected to a strong electric field, thus they are become one of the most promising candidates for high performance capacitors with high-energy storage density and fast discharging rates. ${ }^{-10}$ Significant efforts have been focused on pushing the boundaries of ferroelectric and antiferroelectric design through deepening the understanding of structure-property effects. Engineering crystal structures of low-dimensional (oD to $2 \mathrm{D}$ ) perovskites by employing suitable organic ammonium cations is the predominant methods for the tuning of structure and physical performance. As a booming multifunctional materials, two-dimensional (2D) perovskites, which feature natural quantum-well structures formed by homogeneous integration," alternating and periodic arrangement of semiconducting inorganic layers and capped organic layers at a molecular level, are not subject to the Goldschmidt's factor, that is, they relax structural constrains, and have a wide range of selectivity for the larger, high-aspect ratio, ${ }^{12}$ and potentially functional organic cations, ${ }^{13}$ therefore, they become an ideal choice for ferroelectrics and antiferroelectric. In addition, they also show superior luminescence performance, which inspires further rational structural and property optimization to realize the desirable performance, thus they are widely used in the light-emitting diodes (LEDs), solar cells, lasers and other fields. ${ }^{14-17}$ Generally, the emergence of ferroelectricity or antiferroelectricity is inseparable from phase transitions, changing from a highsymmetry paraelectric phase to a low-symmetry ferroelectric phase, or from a high-symmetry paraelectric phase to a low-symmetry antiferroelectric phase. ${ }^{18-19}$ However, it is scare to achieve a sequence of changes in the identical 2D perovskite from high-symmetry paraelectric phase to a low-symmetry ferroelectric phase to an even lower-symmetric antiferroelectric phase. So far, only a few $2 \mathrm{D}$ perovskites have been reported to have such successive ferroelectric-antiferroelectric-paraelectric phase transitions, for example, $(\mathrm{BA})_{2}(\mathrm{EA})_{2} \mathrm{~Pb}_{3} \mathrm{I}_{10}(\mathrm{BA}=\mathrm{n}-$ butylammonium and $\mathrm{EA}=$ ethylammonium) and (3pyrrolinium) $\mathrm{CdBr}_{3} \cdot{ }^{20-21}$ Herein, we have achieved a successive antiferroelectric-ferroelectric-paraelectric transformation covering a wide temperature range in a $2 \mathrm{D}$ hybrid perovakite $\left[\mathrm{Br}\left(\mathrm{CH}_{2}\right)_{3} \mathrm{NH}_{3}\right]_{2} \mathrm{PbBr}_{4} \quad\left(\mathbf{B P A}-\mathbf{P b B r}_{4}\right)$, 
accompanied by a prominent saturation polrization $\left(P_{s}\right)$ value and a signifcant SHG effect comparable to the standard KDP. Meanwhile, the PL characteristics realized the regulation of broadband emission from blue to white to violet light with temperature stimulation and accompany with the lifetime of microsecond level. This work sheds light on the design of new 


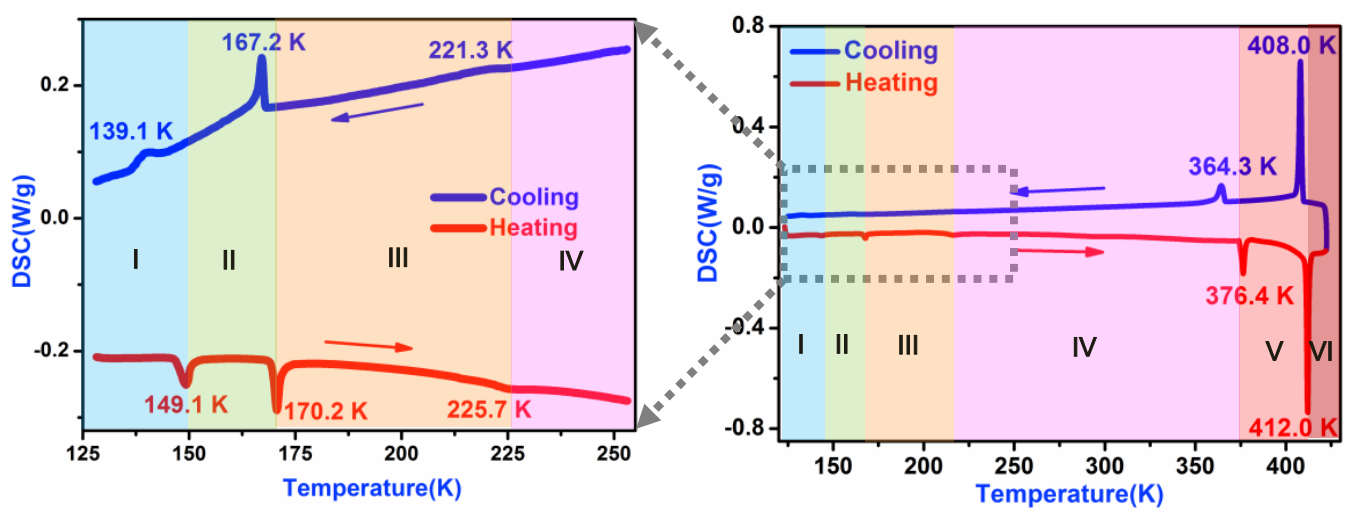

Figure 1. The temperature dependence of heat flows of $\mathbf{B P A}-\mathbf{P b B r} \mathbf{b}_{\mathbf{4}}$, and the left Figure is a larger version of the dotted box on the right.

multifunctional materials and facilitates their application of high-performance devices.

\section{- RESULTS AND DISCUSSION}

The thermodynamic and structural reversibility of BPA$\mathbf{P b B r}_{4}$ were detected by thermal analysis. As shown in Figure 1, the heat flow curves display five pairs of abnormal endothermic and exothermic peaks during heating and cooling runs, respectively, indicating an occurrence of five phase transitions for $\mathbf{B P A}-\mathbf{P b B r}_{4}$. The sharp phase transition peaks between heating and cooling process from high temperature to low temperature indicating that all the peaks exhibited first order phase transition feature except the second order phase transition indicated by the slow peak at $225.7 \mathrm{~K} .{ }^{22-23} \mathrm{We}$ label the phase below 149.1 K as low-temperature (LT) phase I , the phases from 149.1 to $170.2 \mathrm{~K}$ and from 170.2 to $225.7 \mathrm{~K}$ and from 225.7 to $376.4 \mathrm{~K}$ and from 376.4 to 412.0 $\mathrm{K}$ as intermediate-temperature phases II $\sim \mathrm{V}\left(\mathrm{IT}_{1} \sim\right.$ $\mathrm{IT}_{4}$ ), respectively, and the phase above $412.0 \mathrm{~K}$ as the high-temperature (HT) phase VI.

Variable temperature single crystal X-ray diffractions were performed to determine the evolution of crystal structure of each phase with temperature. The crystal structures of $\mathbf{B P A}-\mathbf{P b B r}_{4}$ consist of infinite layers of corner-sharing $\mathrm{PbBr}_{6}$ octahedra charge-compensated by the bilayered organic $\left[\mathrm{Br}\left(\mathrm{CH}_{2}\right)_{3} \mathrm{NH}_{3}\right]^{+}$cations, forming a ${ }_{2} \mathrm{D}$ organic-inorganic layered structure (Figure 2 ). What's interesting is that the first four phases $(I \sim I V)$ of BPA$\mathbf{P b B r}_{4}$ with temperature below $376.4 \mathrm{~K}$ crystalize in noncentrosymmetric polar space groups, while the other two high temperature phases $(\mathrm{V} \sim \mathrm{VI})$ belong to centrosymmetric space groups. Concretely, at LT phase I $(130 \mathrm{~K})$, the symmetry of $\mathbf{B P A}-\mathbf{P b B r}_{4}$ depresses to an orthorhombic antiferroelectric space group $\mathrm{Pca}_{1}$ with cell parameters of $a_{\mathrm{LT}}=27.1474(8), b_{\mathrm{LT}}=16.9201(5), c_{\mathrm{LT}}=$ 7.9011(2) $\AA$ and $V_{\mathrm{LT}}=3629.3(2) \AA 3$ (Table $\mathrm{S} 1$ ). Both the crystallographically independent $\mathrm{Pb} 1$ and $\mathrm{Pb} 2$ ions are sixcoordinated and linked together by sharing one bromine ion. Each ordered $\left[\mathrm{Br}\left(\mathrm{CH}_{2}\right)_{3} \mathrm{NH}_{3}\right]^{+}$cation is hydrogenbonded to the $\mathrm{PbBr}_{6}$ octahedra by four hydrogen bonds with $\mathrm{N} \cdots \mathrm{Br}$ distances in the range of $3.3425(204)$ -
3.5139(197) A (Table S2), and the corresponding $\mathrm{N}-\mathrm{H} \cdots \mathrm{Br}$ angles are in the range of 121.26(126)-179.28(103) ${ }^{\circ}$ (Table $\left.\mathrm{S}_{3}\right)$. Meanwhile, $\mathrm{PbBr}_{6}$ octahedra show a clearly distorted configuration as indicated by the discrepant $\mathrm{Pb} 1-\mathrm{Br}$ bond distances (2.9252(26)-3.0726(26) $\AA$ ) and $\mathrm{Br}-\mathrm{Pb} 1-\mathrm{Br}$ bond angles (82.35(7)-174.72(8) ; and the $\mathrm{Pb} 2-\mathrm{Br}$ lengths spannning from $2.9255(28)$ to $3.0707(26) \AA$ with corresponding $\mathrm{Br}-\mathrm{Pb} 2-\mathrm{Br}$ bond angles in the range of 82.34(7)-174.71 $\left.(8)^{\circ}\right)$. The magnitude of the structural distortion $(\Delta d)$ can be further quantitatively estimated based on the $\mathrm{Pb}-\mathrm{Br}$ bond lengths by the following equation:24-25

$$
\Delta d=\left(\frac{1}{6}\right) \Sigma\left[\frac{d_{n}-\bar{d}}{\bar{d}}\right]^{2}
$$

where $\bar{d}$ is the mean $\mathrm{Pb}-\mathrm{Br}$ distance and $d \mathrm{n}$ is the six individual $\mathrm{Pb}-\mathrm{Br}$ distances. Calculated $\Delta d$ is $3.2302^{*} 10^{-4}$ for $\mathrm{Pb}_{13} \mathrm{Br}_{6}$ and $3.1711^{*}{ }^{-4}{ }^{-4}$ for $\mathrm{Pb}_{2} \mathrm{Br}_{6}$, which is two orders of magnitude higher than the congeneric hybrid perovskites $\left(\mathrm{C}_{4} \mathrm{H}_{9} \mathrm{NH}_{3}\right)_{2} \mathrm{PbCl}_{4} \quad\left(4.3447^{*} 10^{-6}\right)^{26}$ and $\left(2 \mathrm{meptH}_{2}\right) \mathrm{PbBr}_{4}$ (2mept $=2$-methyl-1,5-diamino-pentane $)\left(4.3447^{*} 10^{-6}\right),{ }^{27}$ indicating that $\mathrm{PbBr}_{6}$ octahedron is significant distorted with $\mathrm{Pb}$ atoms deviating from the balanced sites (Figure $\mathrm{Sia})$. In addition, the $\mathrm{Pb}-\mathrm{Br}-\mathrm{Pb}$ angles (157.543 and $157.531^{\circ}$ for $\theta_{1}$ and $138.389^{\circ}$ for $\theta_{2}$ (Tables S2-3)) exhibit large deviation compared with the ideal $180^{\circ}$. At the same time, the two adjacent octahedrons rotated $61.929(59)^{\circ}$ relative to each other, further proofs that the framework is highly distorted (Figure Sib-c). An important characteristic is that the amino groups on the $\left[\mathrm{Br}\left(\mathrm{CH}_{2}\right)_{3} \mathrm{NH}_{3}\right]^{+}$cations are arranged in reverse parallel along the $a$-axis leading to total polarization to zero, which is shown by the arrows in the Figure 2a. Such a remarkable structural distortion synergistically leads to local polarization generation together with the ordering dynamic of organic cation.

As the temperature increases to phase II $\left(\mathrm{IT}_{1}, 160 \mathrm{~K}\right)$, BPA-PbBr ${ }_{4}$ turns to another orthorhombic antiferroelectric space group Pna2 $2_{1}$ with cell parameters of $a_{\mathrm{IT} 1}=b_{\mathrm{LT}}=$ $16.8757(4), b_{\mathrm{IT} 1}=c_{\mathrm{LT}}=7.9609(2), c_{\mathrm{TT} 1}=a_{\mathrm{LT}}=27.1272(5) \AA$ and $V_{\mathrm{IT}_{1}}=3644 \cdot 4(1) \AA 3$ (Table $\mathrm{S} 1$ ). Figure 2a depicts that its perovskite motif is still identified as an octahedral tilting architecture, leading to the emergence of local polarization. Identical as LT phase, $\left[\mathrm{Br}\left(\mathrm{CH}_{2}\right)_{3} \mathrm{NH}_{3}\right]^{+}$ cations are arrangeded in antiparallel is assumed to satisfy 
the requirement of crystallographic symmetry for antipolar order. Meanwhile, ordered $\left[\mathrm{Br}\left(\mathrm{CH}_{2}\right)_{3} \mathrm{NH}_{3}\right]^{+}$ cations are hydrogen-bonded to the $\mathrm{Pb}_{1} \mathrm{Br}_{6}$ and $\mathrm{Pb}_{2} \mathrm{Br}_{6}$ octahedra by two hydrogen bonds with $\mathrm{N}$... $\mathrm{Br}$ distances varing to $3.3435(102)-3.4103(104) \AA$, and the corresponding $\mathrm{N}-\mathrm{H} \cdots \mathrm{Br}$ angles change to $161.473(541)-174.026(535)^{\circ}$, respectively. Besides, the tilting of $\mathrm{PbBr}_{6}$ octahedra also occurs, as verified by the off-center
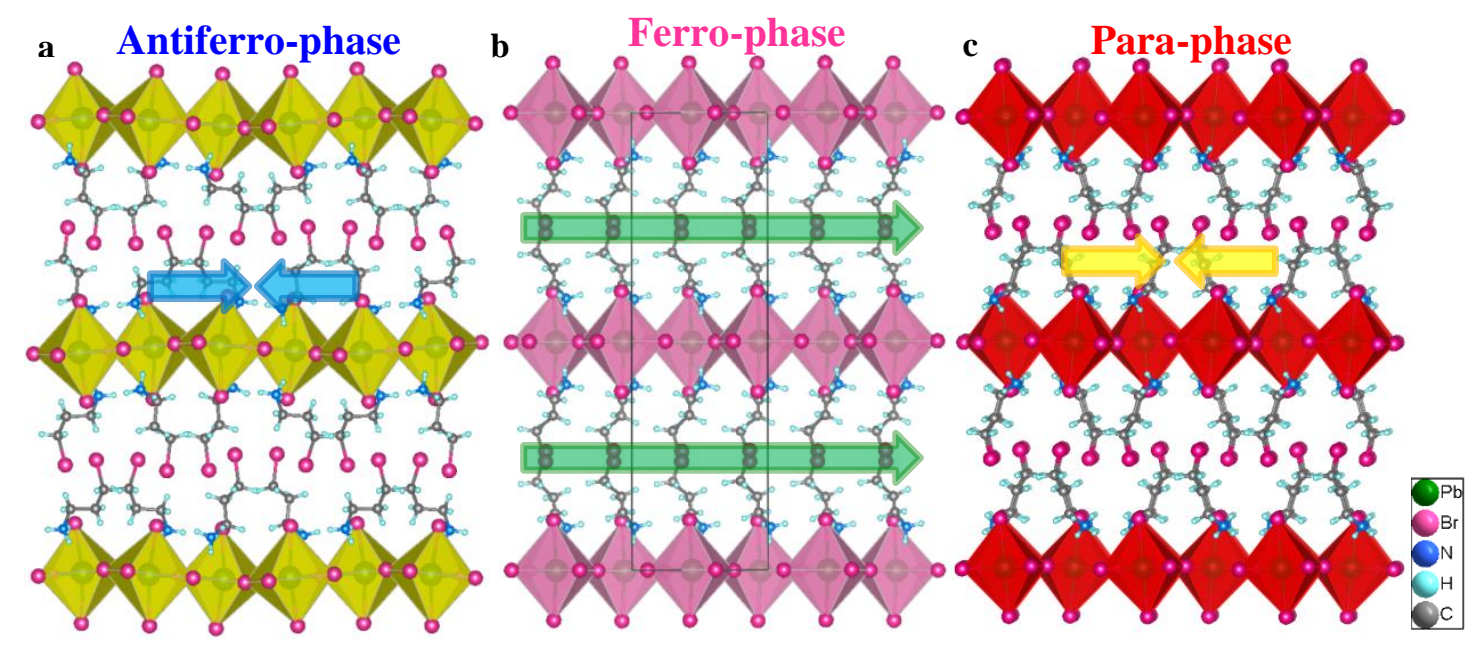

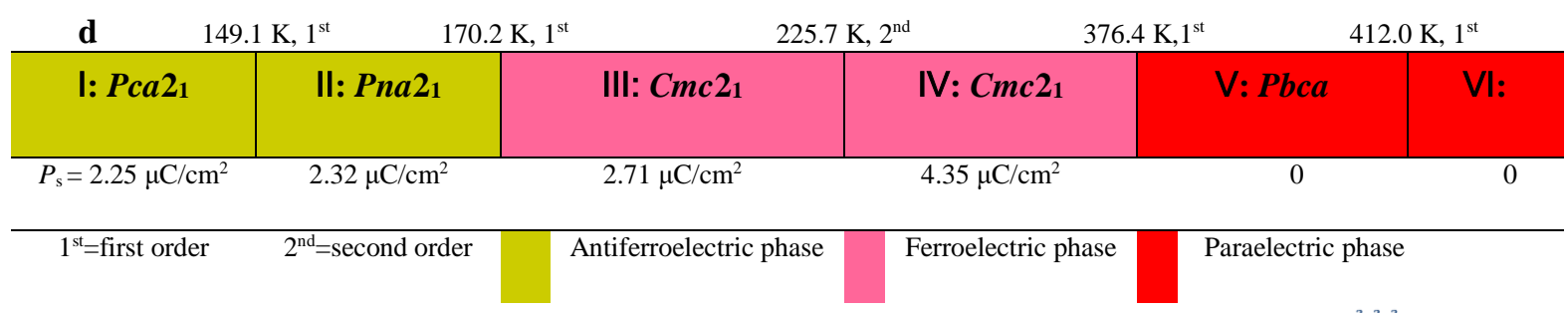
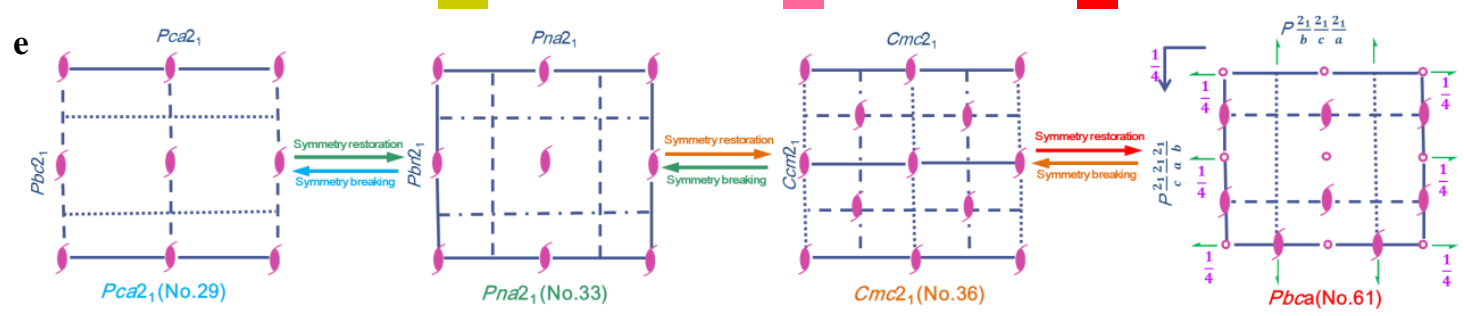

Figure 2. The crystal structures in antiferroelectric (a), ferroelectric (b), and paraelectric (c) phases of $\mathbf{B P A}-\mathbf{P b B r}_{\mathbf{4}}$. The phase diagrams (d) and symmetry breaking (e) of $\mathbf{B P A}-\mathbf{P b B r}_{4}$ in antiferroelectric, ferroelectric and paraelectric phases.

displacements of $\mathrm{Pb}$ ions, and the corresponding $\mathrm{Pb} 1-\mathrm{Br}$ and $\mathrm{Pb} 2-\mathrm{Br}$ bond distances alter to 2.9681(10)-3.0733(13) $\AA$ and 2.9306(10)-3.0752(13) $\AA$, respectively, and $\mathrm{Br}-\mathrm{Pb} 1-\mathrm{Br}$ and $\mathrm{Br}-\mathrm{Pb} 2-\mathrm{Br}$ bond angles transform to $83.24(4)$ $174.93(4)^{\circ}$ and $83.06(4)-175.01(4)^{\circ}$, respectively. Meanwhile, $\Delta d$ is $1.6306^{*} 10^{-4}$ and corresponding $\mathrm{Pb}-\mathrm{Br}-\mathrm{Pb}$ bond angles transform to 157.078 and $157.272^{\circ}$ for $\theta_{1}$ and 139.940 and $139.733^{\circ}$ for $\theta 2$, respectively, and the relative rotation degree of two adjacent octahedrons increases to $61.989(32)^{\circ}$ (Figure Sic), suggesting a reduced distorted geometry.

Further, BPA- $\mathbf{P b B r}_{4}$ tranforms to phase III $\left(\mathrm{IT}_{2}, 200 \mathrm{~K}\right)$ with temperature rises again, accompanied by another orthorhombic ferroelectric space group $\mathrm{Cmc2}_{1}$ with cell parameters of $a_{\mathrm{IT} 2}=27.0935(2), b_{\mathrm{IT} 2}=8.4034(1), c_{\mathrm{IT} 2}=$ 8.0044(1) Å and $V_{\mathrm{IT}_{2}}=1822.42(3) \AA 3$ (Table S1). Unlike the front two phases, ordered $\left[\mathrm{Br}\left(\mathrm{CH}_{2}\right)_{3} \mathrm{NH}_{3}\right]^{+}$cations are arranged parallel along the $c$-axis to meet the crystal symmetry requirements of the polar order and each ordered $\left[\mathrm{Br}\left(\mathrm{CH}_{2}\right)_{3} \mathrm{NH}_{3}\right]^{+}$cation is connected to coincident $\mathrm{PbBr}_{6}$ octahedron via two hydrogen bonds with $\mathrm{N} \cdots \mathrm{Br}$ distances are 3.3887(243) and 3.3784(253) $\AA$, respectively, and the corresponding $\mathrm{N}-\mathrm{H} \cdots \mathrm{Br}$ angles are 151.59 (154) and 165.48(162 $)^{\circ}$, respectively. Meanwhile, $\mathrm{Pb}-\mathrm{Br}$ bond distances, $\mathrm{Br}-\mathrm{Pb}-\mathrm{Br}$ and $\mathrm{Pb}-\mathrm{Br}-\mathrm{Pb}$ bond angles transform to $2.9745(33)-3.0647(26) \quad \AA, \quad 83.97(7)-175.74(8)^{\circ}$ and $141.748(120)$ and $157.071(92)^{\circ}$, respectively (Tables S2-3). Meanwhile, $\Delta d$ is $1.4356^{*} 10^{-4}$, and the relative rotation degree of two adjacent octahedrons isfurther increased to $62.265(68)^{\circ}$, suggesting a minimum distorted geometry.

When the temperature increases further into phase IV $\left(\mathrm{IT}_{3}, 300 \mathrm{~K}\right), \mathbf{B P A}-\mathbf{P b B r}_{4}$ happens a second order phase 
transition so it is still crystalizes in ferroelectric space group $C m \mathrm{C2}_{1}$ with a little bit of variation in the parameters, including cell parameters of $a_{\mathrm{IT}_{3}}=27.2693(11)$, $b_{\mathrm{IT}_{3}}=8.3666(3), c_{\mathrm{IT}_{3}}=8.1321(3) \AA$ and $V_{\mathrm{IT}_{3}}=1855.4(1) \AA^{3}$ (Table S1), N...Br distances are 3.3733(125) and 3.3868(150) $\AA$, and the corresponding $\mathrm{N}-\mathrm{H} \cdots \mathrm{Br}$ angles are $160.73(79)$ and $161.451(947)^{\circ}$, respectively. Meanwhile, $\mathrm{Pb}-\mathrm{Br}$ bond distances, $\mathrm{Br}-\mathrm{Pb}-\mathrm{Br}$ and $\mathrm{Pb}-\mathrm{Br}-\mathrm{Pb}$ bond angles transform to $2.9811(19)-3.070(2) \AA$, 84.13(3)-176.96(5) and 144.821 and $156.474^{\circ}$, respectively (Tables $\mathrm{S}_{2}-3$ ). Meanwhile, $\Delta d$ is $1.3106^{*} 10^{-4}$, and the relative rotation degree of two adjacent octahedrons is further increased to $62.771(48)^{\circ}$ (Figure Sic). Interestingly, the ammonium heads of $\left[\mathrm{Br}\left(\mathrm{CH}_{2}\right)_{3} \mathrm{NH}_{3}\right]^{+}$cation still arrangement stretch down the positive $c$-axis, resulting in the polarization in this positive direction as well in a wide temperature range that spans $150 \mathrm{~K}$ (Figure $2 \mathrm{~b}$ ).
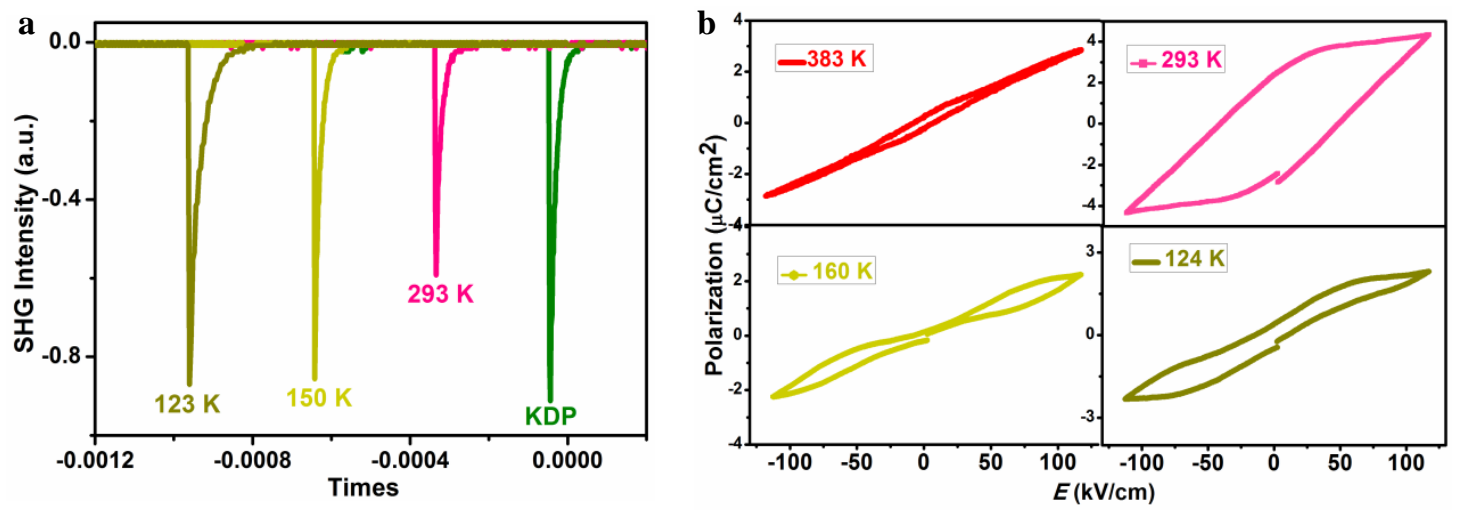

Figure 3. (a) The SHG signals of $\mathbf{B P A}-\mathbf{P b B r}_{4}$ at 123,150 and $293 \mathrm{~K}$, and KDP at $293 \mathrm{~K}$. (b) the $P-E$ hysteresis loops of $\mathbf{B P A}-\mathbf{P b B r}_{4}$ at $383,293,160$ and $124 \mathrm{~K}$.

When the temperature increases further to $390 \mathrm{~K}$ (phase $\mathrm{V}, \mathrm{IT}_{4}$ ), the structure of $\mathbf{B P A}-\mathbf{P b B r}_{4}$ changed significantly, which crystalizes in a centrosymmetry orthorhombic paraelectric space group $\mathrm{Pbca}$ with cell parameters of $a_{\mathrm{IT}_{4}}=b_{\mathrm{IT}_{3}}=8.3991(2), b_{\mathrm{IT}_{4}}=c_{\mathrm{IT}_{3}}=8.2128(2)$, $c_{\mathrm{TT}_{4}}=a_{\mathrm{TT}_{3}}=27.3715(6) \AA$ and $V_{\mathrm{IT}_{4}}=1888.09(7) \AA^{3}$ (Table $\mathrm{S} 1$ ), which is inconsistent with literature report, where reports that the space group is $\mathrm{Cmca} .{ }^{28}$ We tried to refine this into the space group Cmca, but the data is poor. Ordered $\left[\mathrm{Br}\left(\mathrm{CH}_{2}\right)_{3} \mathrm{NH}_{3}\right]^{+}$cations are arranged in reverse to support the disappearance of electric polarization along crystallographic c-axis direction (Figure 2c), thus accompanying the disappearance of ferroelectricity and becoming a paraelectric phase and are connected to coincident $\mathrm{PbBr}_{6}$ octahedron via two hydrogen bonds with $\mathrm{N} \cdots \mathrm{Br}$ distances are 3.4995(188) and 3.3806(175) $\AA$, respectively, and the corresponding $\mathrm{N}-\mathrm{H} \cdots \mathrm{Br}$ angles are 155.68(120) and 120.83(110 $)^{\circ}$, respectively. Meanwhile, $\mathrm{Pb}-$ $\mathrm{Br}$ bond distances, $\mathrm{Br}-\mathrm{Pb}-\mathrm{Br}$ and $\mathrm{Pb}-\mathrm{Br}-\mathrm{Pb}$ bond angles transform to 2.9824(22)-3.0131(17) $\AA, 85.99(6)-180.0(6)^{\circ}$ and $154.638(62)^{\circ}$, respectively (Tables S2-3). Meanwhile, $\Delta d$ is $1.9740^{*} 10^{-5}$, which is an order of magnitude smaller than the octahedral distortion of the other phases indicating a lower degree of distortion. The relative rotation degree of two adjacent octahedrons is further increased to $64.908(40)^{\circ}$ (Figure Sic), suggesting a minimum distorted geometry.
As the temperature goes up and there's a big phase transition at $412 \mathrm{~K}$ (phase VI, HT), however, the acquisition of single crystal data fails due to the high temperature. Other physical properties have been measured to prove that phase VI is still in the paraelectric phase.

All the bond lengths and bond angles as well as $\Delta d$ increase as the temperature increases, indicating that the distortion of the structure decreases from phases I to $\mathrm{V}$. The emergence of polarization relates to the reorientation of organic $\left[\mathrm{Br}\left(\mathrm{CH}_{2}\right)_{3} \mathrm{NH}_{3}\right]^{+}$cations and tilting of inorganic $\mathrm{PbBr}_{6}$ octahedrons, which contributes to the driving force of the phase transition. During this series of phase transitions (Figure 2d), symmetry breaking occurs accompanied with an Aizu notation of $\mathrm{mmmFmm}_{2} \mathrm{Fm}$ from phase $\mathrm{V}$ to phase I according to Landau theory, namely, eight symmetric elements $\left(E, C_{2},{ }_{2} C_{2}^{\prime}, i, \sigma_{h}, 2 \sigma_{v}\right)$ at phase $\mathrm{V}$ are halved into four $\left(E, C_{2}, 2 \sigma_{v}\right)$ at phases III and IV and are further reduced by a quarter into two $\left(E, \sigma_{h}\right)$ at phases I and II (Figure 2e). ${ }^{19,}$ 29-30

Since front four phases I IV of the $\mathbf{B P A}-\mathbf{P b B r}_{4}$ belong to the non-centrosymmetric polar ferroelectric and antiferroelectric space groups, variable temperature SHG and polarization-electric field $(P-E)$ hysteresis loop measurements are used to further verify the correctness of the structures. Figure za displays the SHG signals of $\mathbf{B P A}-\mathrm{PbBr}_{4}$ at 293, 150 and $123 \mathrm{~K}$, respectively, and 
standard potassium dihydrogen phosphate (KDP) at 293 $\mathrm{K}$. The results indicate that the SHG intensities of BPA$\mathbf{P b B r}_{4}$ account for $64.9,93.9$ and $95.4 \%$ of the KDP at 293, 150 and $120 \mathrm{~K}$, respectively, demonstrating the SHG intensity of the $\mathbf{B P A}-\mathbf{P b B r}_{\mathbf{4}}$ is equivalent to that of the KDP in the LT and IT phases, which is attributed to the significant structural distortion of $\mathrm{PbBr}_{6}$ octahedra. Therefore $\mathbf{B P A}-\mathbf{P b B r}_{\mathbf{4}}$ can be widely used as a superior nonlinear material with good purity (Figure S2). However, SHG signals tend to zero in phases V and VI, which is consistent with the assignment of the centrosymmetric structures in these phases.

In addition, the measurement of $P-E$ hysteresis loop is one of the most direct methods to determine the ferroelectricity of materials. Thus the $P-E$ hysteresis loops of BPA-PbBr $\mathbf{r}_{4}$ in six phases were measured. Results indicate that the polarization response to the applied field is linear in phases $\mathrm{V}$ and $\mathrm{VI}$, indicating that these phases belong to paraelectric phase. However, $P-E$ hysteresis loops at 293 and $184 \mathrm{~K}$ behave as ferroelectric phases and accompanying saturation polarization $\left(P_{s}\right)$ values are 4.35 and $2.71 \mu \mathrm{C} / \mathrm{cm}^{2}$, respectively which is consistent with the literature reported $\left(4.8 \mu \mathrm{C} / \mathrm{cm}^{2}\right)^{28}$ and calculated value $(4.88$ $\mu \mathrm{C} / \mathrm{cm}^{2}$ ) according to a point charge model (Figure $\mathrm{S}_{3}$ ). Such spontaneous polarization is consistent with those in other analogous organic-inorganic hybrid perovskite ferroelectrics, such as, $(\mathrm{CHA})_{2} \mathrm{PbBr}_{4-4 \mathrm{x}} \mathrm{I}_{4 \mathrm{x}}(\mathrm{x}=\mathrm{O}-1)(\mathrm{CHA}=$ cyclohexylammonium) $\left(P_{s}=5.8,8.5\right.$, and $7.5 \mu \mathrm{C} \mathrm{cm} \mathrm{cm}^{-2}$ when $\mathrm{x}=0,0.1125$, and 0.175 , respectively), ${ }^{31}$ and significantly less than some organic ferroelectrics $(20 \sim 55$ $\left.\mu \mathrm{C} / \mathrm{cm}^{2}\right)^{32-34}$ and hybrid ferroelectrics $\left(\mathrm{C}_{2} \mathrm{H}_{5} \mathrm{NH}_{3}\right)_{2} \mathrm{CuCl}_{4}(37$ $\left.\mu \mathrm{C} / \mathrm{cm}^{2}\right)$ and $(\mathrm{MV})\left[\mathrm{BiI}_{3} \mathrm{Cl}_{2}\right]\left(\mathrm{MV}^{2+}=\right.$ methylviologen $)(8 \mathrm{o}$ $\left.\mu \mathrm{C} / \mathrm{cm}^{2}\right) .35-36$ What makes $\mathbf{B P A}-\mathbf{P} \mathbf{b B r} \mathbf{r}_{4}$ more intriguing is the emergence of antiferroelectricity as temperature drops evidenced by the notable double $P-E$ hysteresis loops in two low temperature phases, along with the polarization of 2.25 and $2.32 \mu \mathrm{C} / \mathrm{cm}^{2}$, respectively. Such a curious phenomenon contradicts the Kittel prediction that antiferroelectrics generally crystallize in centrosymmetric space group without
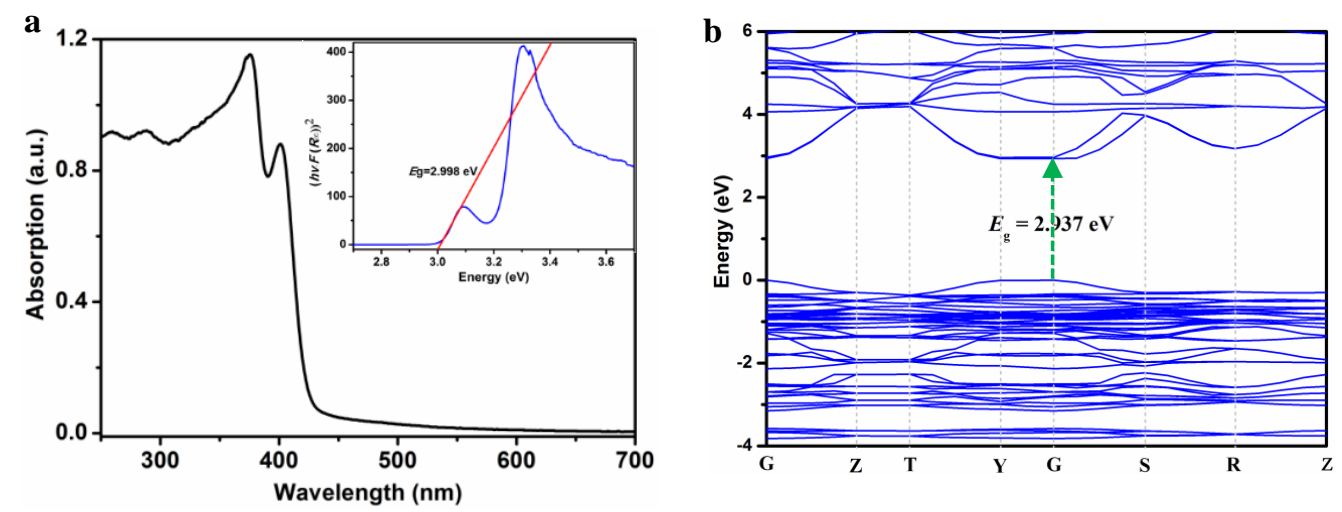

Figure 4. (a) UV-vis absorption spectra and Tauc plot (inset) of BPA-PbBr $\mathbf{r}_{\mathbf{4}}$. (b) The calculated energy band structure for BPA$\mathrm{PbBr}_{4}$.

remnant polarization and SHG response. However, this unusual feature has also been observed in $\mathrm{K}_{3} \mathrm{Nb}_{3} \mathrm{~B}_{2} \mathrm{O}_{12}$ (KNBO) and TCMBI. ${ }^{37-38}$ Meanwhile, we notice that the cell volume of $\mathbf{B P A}-\mathbf{P b B r}_{4}$ in antiferroelectric phases I and II increase to about twice that of ferroelectric and paraelectric phases III $\sim \mathrm{V}$, which is an important microstructure feature to judge antiferroelectric materials. To the best of our knowledge, these polarization values are 
the slightly less than the antiferroelectrics reported so far, including $(\mathrm{BA})_{2}(\mathrm{EA})_{2} \mathrm{~Pb}_{3} \mathrm{I}_{10} \quad\left(5.6 \quad \mu \mathrm{C} / \mathrm{cm}^{2}\right)$, $\left(\left(\mathrm{CH}_{3}\right)_{2} \mathrm{CHCH}_{2} \mathrm{NH}_{3}\right)_{2} \mathrm{CsPbBr}_{7} \quad\left(6.3 \mu \mathrm{C} / \mathrm{cm}^{2}\right)$ and $\left(3^{-}\right.$ pyrrolinium $) \mathrm{CdBr}_{3}\left(7.0 \mu \mathrm{C} / \mathrm{cm}^{2}\right){ }^{20-21}, 39$ Besides, BPA$\mathbf{P b B r}_{4}$ enables an evident energy storage efficiency of $\mathbf{2 8 . 2} \%$, making it a potential candidate for energy storage materials.

Furthermore, we have measured the antiferroelectric double $P$-E hysteresis loops of phases I II at various temperatures during the cooling (Figure $\mathrm{S}_{4} \mathrm{a}$ ) and heating (Figure $\mathrm{S}_{4} \mathrm{~b}$ ) sequences respectively, and ferroelectric $P-E$ hysteresis loops of phases III and IV (Figure $\mathrm{S}_{4}$ c) at various temperatures during the heating sequence. Results indicate that $P_{s}$ in antiferroelectric phases increases slightly as temperature decreases during cooling in the range of 108$164 \mathrm{~K}$, but remains almost unchanged during heating in the range of 117-168 K, while $P_{s}$ increases with the raise of temperature in the whole ferroelectric phases in the range of $197-369 \mathrm{~K}$.

Depending on the excellent ferroelectric and antiferroelectric properties of $\mathbf{B P A}-\mathbf{P b B r}_{\mathbf{4}}$, and $\mathrm{Pb}$-based $2 \mathrm{D}$ organic-inorganic hybrid perovskites are expected to have potential semiconductiong properties, UV-Vis absorption spectrum at room temperature was carried out to investigate the electronic structures and photophysical properties of $\mathbf{B P A}-\mathbf{P b B r}_{4}$. Result reveals a steep absorption edge at $410 \mathrm{~nm}$, indicating $\mathbf{B P A}-\mathbf{P b B r} \mathbf{r}_{\mathbf{4}}$ is a direct band gap semiconductor with corresponding band gap of $2.998 \mathrm{eV}$ by fitting absorption curve with Tauc equation, $4^{\circ}$ which is consistent with the literature report. ${ }^{28}$ In addition, a shoulder peak appears at around $400 \mathrm{~nm}$ in the absorption spectrum, indicating BPA$\mathbf{P b B r}_{4}$ has distinct excition features near the absorption edge, where the low dielectric constant of the organic layer and $2 \mathrm{D}$ structure of the inorganic layers leads to enhancement of the attraction between the electron and hole in an exciton.

To uncover the electronic origin micro-mechanism of band gap, we calculated the electronic band structures and partial density of states (PDOS) of BPA-PbBr $\mathbf{B}_{\mathbf{4}}$ based on density functional theory (DFT) calculations. As shown in Figure 4 b, BPA-PbBr${ }_{4}$ shows a direct band gap at the Brillouin zones $G$ point with energy value of $\mathbf{2 . 9 3 7}$ $\mathrm{eV}$, which is slightly lower than the experimental value and that's because the known generalized gradient approximation (GGA) functional underestimates the band gap. Meanwhile, PDOS plot shows that the valence band maximum of $\mathbf{B P A}-\mathbf{P b B r}_{4}$ except dominated by $\mathrm{Br}-4 \mathrm{P}$ orbitals, and bits of $\mathrm{Pb}-6 \mathrm{~s}, \mathrm{~N}-2 \mathrm{p}, \mathrm{C}-2 \mathrm{p}$ and $\mathrm{H}-1 \mathrm{~s}$ are also involved, while the $\mathrm{Pb}-6 \mathrm{p}$ orbital spans the entire band gap and conduction band minimum, which indicates that the inorganic $\mathrm{PbBr}_{6}$ octahedron is responsible for band gap (Figure $\mathrm{S}_{5}$ ). These results are obviously identical to the most of the reported metal-halide perovskites.

High distortion of lead-halide octahedron in organicinorganic hybrid pervoskites not only contributes to the prominent ferroelectricity, but also associates with the great potential of photoluminescence (PL) emission, which induces the self-trapped excitons generaged from recombination of excitons-hole pairs through strong electron-phonon coupling. ${ }^{41-43}$ PL spectra of $\mathbf{B P A}-\mathbf{P b B r}_{4}$ at six phases are measured and shown in Figure $5 \mathrm{a}$, results express that the emission wavelength centers are 404 and $405 \mathrm{~nm}$ at 130 and $160 \mathrm{~K}$, respectively, with the full width at half-maximum (FWHM) are 17 and $18 \mathrm{~nm}$, respectively, which is almost unchanged in the two low temperature phases ( I and II). However, the emission wavelength shows a broadband emission with center wavelength redshifted to $431 \mathrm{~nm}$ at $293 \mathrm{~K}$ (phase IV), which proves that the emission peak position red-shifted $27 \mathrm{~nm}$ due to temperature stimulation. Meanwhile, the FWHM is broaden to $80 \mathrm{~nm}$ at $293 \mathrm{~K}$, which is attributed to the increase of thermal filling vibration dynamics at high temperature. Oddly enough, as the temperature rises to the phases $\mathrm{V}$ and VI, the emission wavelength centers blue-shifted back to 373 and $372 \mathrm{~nm}$ with FWHM of 38 and $20 \mathrm{~nm}$, respectively. The temperature dependence of the PL emission wavelength is a consequence of both the electron-phonon interaction and the lattice expansion. Generally, the lattice expansion leads to a red-shift with increasing temperature, while the electron-phonon interaction causes a blue-shift. Thus, BPA-PbBr $\mathbf{r}_{4}$ occurs a red-shift between phases I and IV, where the influence of lattice expansion exceeds the contribution of the electron-phonon interaction, due to the lattice exhibits a nonlinear expansion. On the contrary, the electronphonon interaction becomes the dominating process leading to a blue-shift in phases $\mathrm{V}$ and VI attributed to the lattice expansion slows down and becomes linear. 

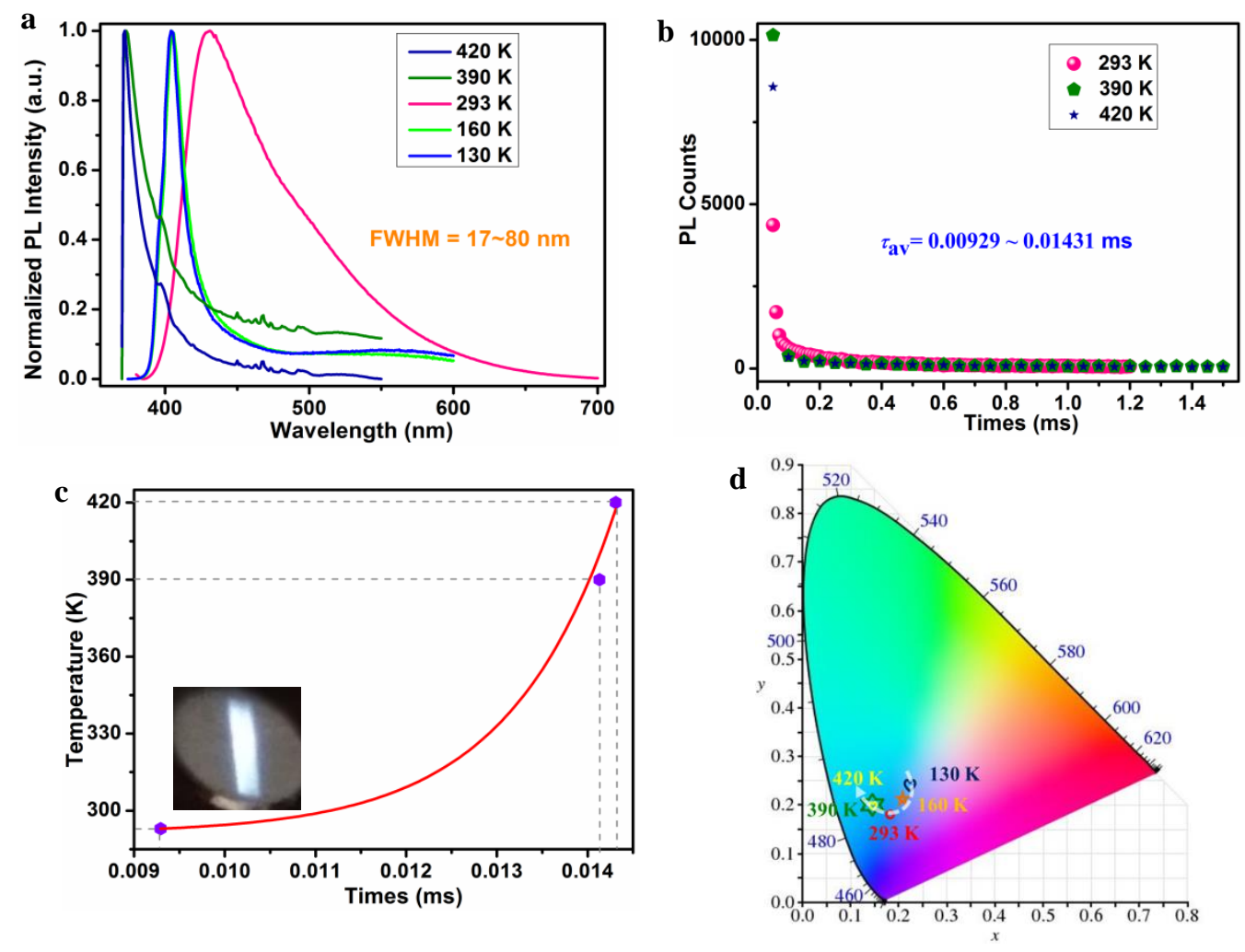

Figure 5. (a) PL spectra of BPA-PbBr 4 at 130, 160, 293, 390 and $420 \mathrm{~K}$, respectively. (b-c) The time-resolved PL spectra of BPA$\mathbf{P b B r}_{4}$ at 293, 390 and $420 \mathrm{~K}$, respectively. The inserted image in (c) represents a PL photograph of $\mathbf{B P A}-\mathbf{P b B r}$ at $293 \mathrm{~K}$. (d) CIE color coordinates of BPA-PbBr 4 in 1931 color chromaticity diagram at different temperature.

Time-resolved PL spectrum of $\mathbf{B P A}-\mathbf{P b B r}_{4}$ uncovers that average lifetime $\left(\tau_{\mathrm{av}}\right)$, which is determined by the speed of positive and negative exciton recombination, in the range of $9.29 \sim 14.31 \mu$ s between $293 \sim 420 \mathrm{~K}$ by fitting the PL decay curve with biexponential function (Figures 5b-c). In addition, the commission International de I'Eclairage (CIE) color coordinates of $\mathbf{B P A}-\mathbf{P b B r}_{4}$ at six phases shift from close to the center to the edge region in the 1931 color space chromaticity diagram. As shown in Figure $5 \mathrm{~d}$, the CIE coordinates are $(0.15,0.20),(0.15,0.20)$, (o.19, 0.18), (o.21, 0.21) and (o.23, 0.24) at 420, 390, 293, 16o and $130 \mathrm{~K}$, respectively, which indicates that can provide an effective way to prepare blue-light semiconductor devices.

As shown in the image inserted in Figure 5c, BPA$\mathbf{P b B r}_{4}$ displays a bright white light in the center surrounded by blue light at $293 \mathrm{~K}$, which has great potential for application in light emitting diode (LED) due to $2 \mathrm{D}$ perovskites feature natural quantum-well structures formed by alternating and periodic arrangement of bulky organic layers and inorganic layers. In addition, $\mathbf{B P A}-\mathbf{P b B r}_{4}$ exhibits a moderate photoluminescence quantum efficiency of $1.79 \%$ at $293 \mathrm{~K}$, which is comparable to other analogous broadband emmision organic-inorganic hybrid perovskites including $\left(\mathrm{C}_{4} \mathrm{H}_{9} \mathrm{NH}_{3}\right)_{2} \mathrm{PbCl}_{4}(1 \%),{ }^{26}(\mathrm{~N}-\mathrm{MEDA}=\mathrm{N}$-methylethane-1,2diammonium) $\left[\mathrm{PbBr}_{4}\right]$ (o.5\%), ${ }^{44}$ but much lower than some similar organic-inorganic hybrid perovskite ( $\mathrm{N}_{1}-$ methylethane-1,2-diammonium) $\left[\mathrm{PbBr}_{4-\mathrm{x}} \mathrm{Cl}_{\mathrm{x}}\right]$ and $\left(\mathbf{2 , 2} \mathbf{2}^{\prime}-\right.$ (ethylenedioxy)bis(ethylammonium)) $\left[\mathrm{PbX}_{4}\right]$ with $\mathrm{X}=\mathrm{Cl}$ or $\mathrm{Br}(9 \%) .45$ This low PLQYs may be attributed to insufficient confinement of Wannier type excitons within the inorganic layers. ${ }^{46-47}$

\section{- CONCLUSION}

In summary, five successive phase transitions occur in a $2 \mathrm{D}$ organic-inorganic hybrid perovskite, $\left[\mathrm{Br}\left(\mathrm{CH}_{2}\right)_{3} \mathrm{NH}_{3}\right]_{2} \mathrm{PbBr}_{4}$ (BPA-PbBr $\left.\mathbf{r}_{4}, \mathrm{BPA}=\mathrm{Br}\left(\mathrm{CH}_{2}\right)_{3} \mathrm{NH}_{3}\right)$, accompanied by a series of changes from paraelectric to ferroelectric to antiferroelectric phase transitions, and saturation polarization $\left(P_{\mathrm{s}}\right)$ values also change from o to 4.35 to $2.25 \mu \mathrm{C} / \mathrm{cm}^{2}$, respectively. Further, $\mathbf{B P A}-\mathbf{P b B r}_{4}$ has superior SHG characteristics, accounting for $95 \%$ of the standard KDP. In addition, the photoluminescence (PL) properties of $\mathbf{B P A}-\mathbf{P b B r}_{4}$ also undergo a peculiar transformation under the influence of both the electron-phonon interaction and the lattice expansion, which occurs red-shift at the beginning as the temperature increases from 130 to $376 \mathrm{~K}$, and followed by blue-shifted as temperature increases further from 376 to $420 \mathrm{~K}$. Besides, BPA$\mathrm{PbBr}_{4}$ exhibits a broadband emission with a bright white light at room temperature, accompanied by quantum efficiency is $1.79 \%$. This discovery paves an avenue to search for multifunctional hybrid perovskites and provides the impetus for further optoelectronic industrial applications. 


\section{- ASSOCIATED CONTENT}

\section{Supporting Information.}

The Supporting Information is available free of charge via the Internet at http://pubs.acs.org.

Figures S1-5: the schematic of octahedral distortion, $\mathrm{Pb}-\mathrm{Br}-$ $\mathrm{Pb}$ angles and rotation degree of two adjacent octahedrons in antiferroelectric, ferroelectric and paraelectric phases; powder XRD pattern; distribution of $\mathrm{Pb}$ and $\mathrm{N}$ atoms in a unit cell; $P$ - $E$ hysteresis loops of antiferroelectric and ferroelectric phases at various temperatures; the calculated partial density of states (PDOS) for BPA-PbBr . $_{4}$.

Tables S1-3: crystal data and structure refinement details for $\mathbf{B P A}-\mathbf{P b B r}_{4}$; the bond lengths $(\AA)$ and bond angles $\left(^{\circ}\right)$ of BPA-PbBr 4 at different temperature.

\section{AUTHOR INFORMATION}

\section{Corresponding Author \\ *E-mail: wwenjuan2o@163.com (W. W. J.). \\ *E-mail: tangyunzhi75@163.com (T. Y. Z.).}

\section{Notes}

The authors declare no competing financial interest.

\section{ACKNOWLEDGMENT}

The authors acknowledge funding support from the National Natural Science Foundation of China (Grant Nos. 22001102, 21761013 and 21671086) and the Jiangxi Provincial Natural Science Foundation Grant (No. 20202BAB213002) and the Education department of Jiangxi province (No. 204201400631) and the Fundamental Research Funds for the Central Universities (Jiangxi University of Science and Technology, No. 205200100116) and Program for Excellent Young Talents, JXUST.

\section{REFERENCES}

(1) Chu, B.; Zhou, X.; Ren, K.; Neese, B.; Lin, M.; Wang, Q.; Bauer, F.; Zhang, Q. M., A Dielectric Polymer with High Electric Energy Density and Fast Discharge Speed. Science 2006, 313, (5785), 334-336.

(2) Larcher, D.; Tarascon, J. M., Towards greener and more sustainable batteries for electrical energy storage. Nat. Chem. 2015, 7, (1), 19-29.

(3) Ji, C.; Sun, Z.; Zeb, A.; Liu, S.; Zhang, J.; Hong, M.; Luo, J., Bandgap Narrowing of Lead-Free Perovskite-Type Hybrids for Visible-Light-Absorbing Ferroelectric Semiconductors. J. Phys. Chem. Lett. 2017, 8, (9), 2012-2018.

(4) Li, L.; Shang, X.; Wang, S.; Dong, N.; Ji, C.; Chen, X.; Zhao, S.; Wang, J.; Sun, Z.; Hong, M.; Luo, J., Bilayered Hybrid Perovskite Ferroelectric with Giant Two-Photon Absorption. J. Am. Chem. Soc. 2018, 140, (22), 6806-6809.

(5) You, Y.-M.; Liao, W.-Q.; Zhao, D.; Ye, H.-Y.; Zhang, Y.; Zhou, Q.; Niu, X.; Wang, J.; Li, P.-F.; Fu, D.-W., An organicinorganic perovskite ferroelectric with large piezoelectric response. Science 2017, 357, (6348), 306-309.

(6) Garcia, V.; Fusil, S.; Bouzehouane, K.; Enouz-Vedrenne, S.; Mathur, N. D.; Barthélémy, A.; Bibes, M., Giant tunnel electroresistance for non-destructive readout of ferroelectric states. Nature 2009, 460, 81-84.
(7) Kittel, C., Theory of Antiferroelectric Crystals. Phys. Rev. 1951, 82, (5), 729-732.

(8) Li, J.; Li, F.; Xu, Z.; Zhang, S., Multilayer Lead-Free Ceramic Capacitors with Ultrahigh Energy Density and Efficiency. Adv. Mater. 2018, 30, (32), e1802155.

(9) Zhao, L.; Liu, Q.; Gao, J.; Zhang, S.; Li, J., Lead-Free Antiferroelectric Silver Niobate Tantalate with High Energy Storage Performance. Adv. Mater. 2017, 29, (31), 1701824.

(10) Liu, Z.; Lu, T.; Ye, J.; Wang, G.; Dong, X.; Withers, R.; Liu, Y., Antiferroelectrics for Energy Storage Applications: a Review. Adv. Mater. Technol-us. 2018, 3, (9), 1800111.

(11) Even, J.; Pedesseau, L.; Katan, C., Understanding quantum confinement of charge carriers in layered $2 \mathrm{D}$ hybrid perovskites. Chemphyschem 2014, 15, (17), 3733-3741.

(12) Tan, C.; Cao, X.; Wu, X. J.; He, Q.; Yang, J.; Zhang, X.; Chen, J.; Zhao, W.; Han, S.; Nam, G. H.; Sindoro, M.; Zhang, H., Recent Advances in Ultrathin Two-Dimensional Nanomaterials. Chem. Rev. 2017, 117, (9), 6225-6331.

(13) Jemli, K.; Audebert, P.; Galmiche, L.; Trippe-Allard, G.; Garrot, D.; Lauret, J. S.; Deleporte, E., Two-Dimensional Perovskite Activation with an Organic Luminophore. ACS Appl. Mater. Inter. 2015, 7, (39), 21763-21769.

(14) Kawano, N.; Koshimizu, M.; Sun, Y.; Yahaba, N.; Fujimoto, Y.; Yanagida, T.; Asai, K., Effects of Organic Moieties on Luminescence Properties of Organic-Inorganic Layered Perovskite-Type Compounds. J.Phys. Chem. C. 2014, 118, (17), 9101-9106.

(15) Wei, Y.; Audebert, P.; Galmiche, L.; Lauret, J. S.; Deleporte, E., Synthesis, optical properties and photostability of novel fluorinated organic-inorganic hybrid $\left(\mathrm{R}-\mathrm{NH}_{3}\right)_{2} \mathrm{PbX}_{4}$ semiconductors. J. Phys.D: Appl. Phys. 2013, 46, (13), 135105.

(16) Smith, I. C.; Hoke, E. T.; Solis-Ibarra, D.; McGehee, M. D.; Karunadasa, H. I., A layered hybrid perovskite solar-cell absorber with enhanced moisture stability. Angew. Chem. Int. Ed. 2014, 53, (42), 11232-11235.

(17) Stoumpos, C. C.; Cao, D. H.; Clark, D. J.; Young, J.; Rondinelli, J. M.; Jang, J. I.; Hupp, J. T.; Kanatzidis, M. G., Ruddlesden-Popper Hybrid Lead Iodide Perovskite 2D Homologous Semiconductors. Chem. Mater. 2016, 28, (8), 2852-2867.

(18) Sun, Z.; Li, J.; Ji, C.; Sun, J.; Hong, M.; Luo, J., Unusual Long-Range Ordering Incommensurate Structural Modulations in an Organic Molecular Ferroelectric. J. Am. Chem. Soc. 2017, 139, (44), 15900-15906.

(19) Shi, P. P.; Tang, Y. Y.; Li, P. F.; Liao, W. Q.; Wang, Z. X.; Ye, Q.; Xiong, R. G., Symmetry breaking in molecular ferroelectrics. Chem. Soc. Rev. 2016, 45, (14), 3811-3827.

(20) Han, S.; Liu, X.; Liu, Y.; Xu, Z.; Li, Y.; Hong, M.; Luo, J.; Sun, Z., High-Temperature Antiferroelectric of Lead Iodide Hybrid Perovskites. J. Am. Chem. Soc. 2019, 141, (32), 1247012474.

(21) Li, P. F.; Liao, W. Q.; Tang, Y. Y.; Ye, H. Y.; Zhang, Y.; Xiong, R. G., Unprecedented Ferroelectric-AntiferroelectricParaelectric Phase Transitions Discovered in an OrganicInorganic Hybrid Perovskite. J. Am. Chem. Soc. 2017, 139, (25), 8752-8757.

(22) Li, C.; Li, L.-S.; Wei, W.-J.; Tan, Y.-H., A Temperatural Semi-Memorized Phase Transition in a $1 \mathrm{D}$ Organic-Inorganic Hybrid Material of Sblll-Based $\left[\left(\mathrm{CH}_{2}\right)_{3} \mathrm{NH}_{2} \mathrm{~S}\right]_{2} \mathrm{SbCl}_{5}$. Inorg. Chem. 2019, 58, (15), 9733-9737.

(23) Gao, H.-Q.; Wei, W.-J.; Tan, Y.-H.; Tang, Y.-Z., Phase Transition and Negative Thermal Expansion in Guanidinium 
Magnesium-Hypophosphite Hybrid Perovskite. Chem. Mater. 2020, 32, 6886-6891.

(24) Du, K. Z.; Tu, Q.; Zhang, X.; Han, Q.; Liu, J.; Zauscher, S.; Mitzi, D. B., Two-Dimensional Lead(II) Halide-Based Hybrid Perovskites Templated by Acene Alkylamines: Crystal Structures, Optical Properties, and Piezoelectricity. Inorg. Chem. 2017, 56, (15), 9291-9302.

(25) Alonso, J. A.; Martinezlope, M. J.; Casais, M. T.; Fernandezdiaz, M. T., Evolution of the Jahn-Teller Distortion of $\mathrm{MnO}_{6}$ Octahedra in $\mathrm{RMnO}_{3}$ Perovskites $(\mathrm{R}=\mathrm{Pr}$, Nd, Dy, Tb, Ho, Er, Y): A Neutron Diffraction Study. Inorg. Chem. 2ooo, 39, (5), 917-923.

(26) Ji, C.; Wang, S.; Li, L.; Sun, Z.; Hong, M.; Luo, J., The First 2D Hybrid Perovskite Ferroelectric Showing Broadband White-Light Emission with High Color Rendering Index. Adv Funct. Mater. 2018, 29, (6), 1805038.

(27) Wang, S.; Yao, Y.; Kong, J.; Zhao, S.; Sun, Z.; Wu, Z.; Li, L.; Luo, J., Highly efficient white-light emission in a polar two-dimensional hybrid perovskite. Chem. Commun. 2018, 54, (32), 4053-4056.

(28) Luo, J.; Ji, C.; Dey, D.; Peng, Y.; Liu, X.; Li, L., Ferroelectricity-Driven Self-Powered Ultraviolet Photodetection with Strong Polarization-Sensitivity in a Two-Dimensional Halide Hybrid Perovskite. Angew. Chem. Int. Ed. 2020.

(29) Aizu, K., Possible Species of "Ferroelastic" Crystals and of Simultaneously Ferroelectric and Ferroelastic Crystals. J. Phys. Soc. Jap. 1969, 27, (2), 387-396.

(30) Zhang, W.; Xiong, R. G., Ferroelectric metal-organic frameworks. Chem. Rev. 2012, 112, (2), 1163-1195.

(31) Ye, H. Y.; Liao, W. Q.; Hu, C. L.; Zhang, Y.; You, Y. M.; Mao, J. G.; Li, P. F.; Xiong, R. G., Bandgap Engineering of Lead-Halide Perovskite-Type Ferroelectrics. Adv. Mater. 2016, 28, (13), 2579-2586.

(32) Fu, D. W.; Cai, H. L.; Liu, Y.; Ye, Q.; Zhang, W.; Zhang, Y.; Chen, X. Y.; Giovannetti, G.; Capone, M.; Li, J.; Xiong, R. G., Diisopropylammonium bromide is a high-temperature molecular ferroelectric crystal. Science 2013, 339, (6118), 425428.

(33) Tayi, A. S.; Shveyd, A. K.; Sue, A. C.; Szarko, J. M.; Rolczynski, B. S.; Cao, D.; Kennedy, T. J.; Sarjeant, A. A.; Stern, C. L.; Paxton, W. F.; Wu, W.; Dey, S. K.; Fahrenbach, A. C.; Guest, J. R.; Mohseni, H.; Chen, L. X.; Wang, K. L.; Stoddart, J. F.; Stupp, S. I., Room-temperature ferroelectricity in supramolecular networks of charge-transfer complexes. Nature 2012, 488, (7412), 485-489.

(34) Horiuchi, S.; Tokunaga, Y.; Giovannetti, G.; Picozzi, S.; Itoh, H.; Shimano, R.; Kumai, R.; Tokura, Y., Above-roomtemperature ferroelectricity in a single-component molecular crystal. Nature 2010, 463, (7282), 789-792.

(35) Kundys, B.; Lappas, A.; Viret, M.; Kapustianyk, V.; Rudyk, V.; Semak, S.; Simon, C.; Bakaimi, I., Multiferroicity and hydrogen-bond ordering in $\left(\mathrm{C}_{2} \mathrm{H}_{5} \mathrm{NH}_{3}\right)_{2} \mathrm{CuCl}_{4}$ featuring dominant ferromagnetic interactions. Phys. Rev. $B$ 2o10, 81, (22).

(36) Leblanc, N.; Mercier, N.; Zorina, L.; Simonov, S.; AubanSenzier, P.; Pasquier, C., Large spontaneous polarization and clear hysteresis loop of a room-temperature hybrid ferroelectric based on mixed-halide $\left[\mathrm{BiI}_{3} \mathrm{Cl}_{2}\right]$ polar chains and methylviologen dication. J. Am. Chem. Soc. 2011, 133, (38), 14924-14927.

(37) Shan, P.; Xiong, J.; Wang, Z.; He, C.; Yang, X.; Su, R.; Long, $\mathrm{X}$., Lead-free polar borate crystal $\mathrm{K}_{3} \mathrm{Nb}_{3} \mathrm{~B}_{2} \mathrm{O}_{12}$ : a novel antiferroelectric structure type. J. Mater. Chem. C 2020, 8, 6654-6658.

(38) Horiuchi, S.; Kagawa, F.; Hatahara, K.; Kobayashi, K.; Kumai, R.; Murakami, Y.; Tokura, Y., Above-roomtemperature ferroelectricity and antiferroelectricity in benzimidazoles. Nat. Commun. 2012, 3, 1308.

(39) Wu, Z.; Liu, X.; Ji, C.; Li, L.; Wang, S.; Peng, Y.; Tao, K.; Sun, Z.; Hong, M.; Luo, J., Discovery of an Above-RoomTemperature Antiferroelectric in Two-Dimensional Hybrid Perovskite. J. Am. Chem. Soc. 2019, 141, (9), 3812-3816.

(40) Tauc, J., Absorption edge and internal electric fields in amorphous semiconductors. Mater. Res. Bull. 1970, 5, (8), 721-729.

(41) Hu, T.; Smith, M. D.; Dohner, E. R.; Sher, M.-J.; Wu, X.; Trinh, M. T.; Fisher, A.; Corbett, J.; Zhu, X. Y.; Karunadasa, H. I.; Lindenberg, A. M., Mechanism for Broadband WhiteLight Emission from Two-Dimensional (110) Hybrid Perovskites. J. Phys. Chem. Lett. 2016, 7, (12), 2258-2263.

(42) Cortecchia, D.; Yin, J.; Bruno, A.; Lo, S.-Z. A.; Gurzadyan, G. G.; Mhaisalkar, S.; Brédas, J.-L.; Soci, C., Polaron selflocalization in white-light emitting hybrid perovskites. J. Mater. Chem. C. 2017, 5, (11), 2771-2780.

(43) Thirumal, K.; Chong, W. K.; Xie, W.; Ganguly, R.; Muduli, S. K.; Sherburne, M.; Asta, M.; Mhaisalkar, S.; Sum, T. C.; Soo, H. S.; Mathews, N., Morphology-Independent Stable White-Light Emission from Self-Assembled TwoDimensional Perovskites Driven by Strong Exciton-Phonon Coupling to the Organic Framework. Chem. Mater. 2017, 29, (9), 3947-3953.

(44) Dohner, E. R.; Hoke, E. T.; Karunadasa, H. I., Selfassembly of broadband white-light emitters. J. Am. Chem. Soc. 2014, 136, (5), 1718-1721.

(45) Dohner, E. R.; Jaffe, A.; Bradshaw, L. R.; Karunadasa, H. I., Intrinsic white-light emission from layered hybrid perovskites. J. Am. Chem. Soc. 2014, 136, (38), 13154-13157.

(46) Yu, J.; Kong, J.; Hao, W.; Guo, X.; He, H.; Leow, W. R.; Liu, Z.; Cai, P.; Qian, G.; Li, S.; Chen, X.; Chen, X., Broadband Extrinsic Self-Trapped Exciton Emission in Sn-Doped 2D Lead-Halide Perovskites. Adv. Mater. 2o19, 31, (7), e1806385. (47) Ogawa, T. A. K., Y, Optical Properties of LowDimensional Materials. Singapore 1995. 
Insert Table of Contents artwork here

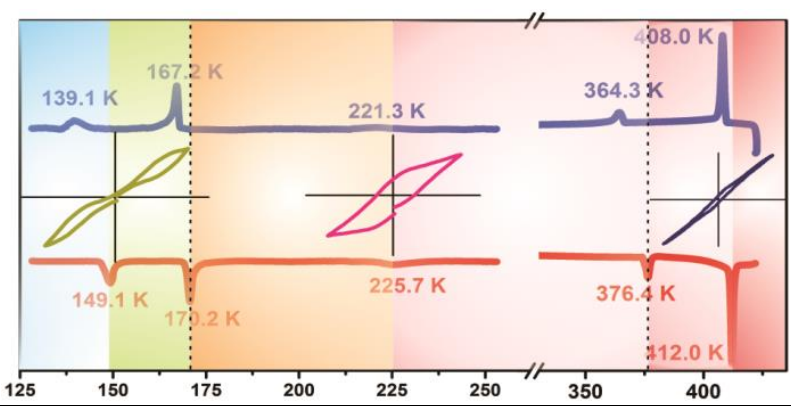

